\title{
Variation in Polyol Levels in Cerebrospinal Fluid and Serum in Diabetic Patients
}

\author{
C. Servo and E. Pitkänen \\ Fourth Dept. of Medicine, Univ. of Helsinki, Helsinki, Finland
}

Received: October 21, 1974, and in revised form: September 19, 1975

\begin{abstract}
Summary. Cerebrospinal fluid (CSF) or CSF and plasma levels of sorbitol, 1,5-anhydroglucitol and myoinositol of diabetic and nondiabetic patients with normal kidney function and of diabetic and non-diabetic patients with impaired kidney function were measured by gas-liquid chromatography. The CSF sorbitol level correlated with the plasma glucose level $(p \leqq 0.05)$ in diabetic patients with normal kidney function, having received insulin for less than 12 months. The correlation between CSF sorbitol and plasma glucose levels in patients not dependent on insulin was not significant. Sorbitol was not detected in the plasma. The highest sorbitol levels in CSF were seen in insulin-dependent diabetic patients with impaired kidney function. No rise was seen in non-diabetic uremia. 1,5-anhydroglucitol, normally present in plasma, was absent from CSF and plasma in diabetic patients receiving insulin. In non-diabe-
\end{abstract}

tic uremic patients 1,5-anhydroglucitol levels in CSF and plasma were lower than in healthy subjects, but there was no correlation with plasma glucose levels. The myoinositol level was higher in CSF than in the plasma of both non-diabetic and diabetic patients with normal kidney function. Both plasma and CSF levels were significantly $(p<0.001)$ elevated in diabetic as well as in non-diabetic uremic patients, the plasma myoinositol increasing relatively more than the CSF levels. The elevation of plasma myoinositol correlated with the elevation of plasma creatinine and thus also with the impairment of kidney function. Plasma and CSF myoinositol levels were not influenced by the plasma glucose level.

Key words: 1,5-anhydroglucitol, myoinositol, sorbitol, diabetes, uremia.
The presence of the polyol pathway has been demonstrated in several tissues including the spinal cord and kidneys [1]. Sorbitol accumulation in the tissues has been regarded to be primarily controlled by the blood glucose level and the activity of aldose reductase (1.1.1.21.) [1,2]. The activity of aldose reductase is increased in the Schwann cells in the nerves of diabetic rats $[1,3]$. The accumulation of sorbitol in monkey kidney epithelial cell cultures by means of the polyol pathway has been demonstrated [4]. 1,5-anhydroglucitol is normally present in CSF and in plasma [8] but seems to be absent from CSF in diabetic patients receiving insulin and low in advanced stages of uremia. Myoinositol induces neural dysfunction in test animals [5] and diabetic patients are intolerant to orally administered myoinositol [6]. The plasma myoinositol level is elevated in uremia [7].

As an attempt to illuminate further the relationship between changes in the polyol levels in diabetic and uremic patients we measured sorbitol, 1,5-anhydroglucitol and myoinositol levels in CSF and plasma of diabetic and non-diabetic patients with normal kidney function. A correlation was sought between polyol levels and glucose levels in plasma and CSF. An increase in the concentration of CSF polyols was compared with the type of treatmient and duration of diabetes. The results were also compared with those from diabetic and non-diabetic patients with impaired kidney function.

\section{Material and Methods}

\section{Patients}

61 diabetic patients with normal kidney function were studied. The mean age of the patients was $61.7 \pm$ 15.5 years, their height $166.0 \pm 9.5 \mathrm{~cm}$ and mean body weight $104 \%$ of the body weight normally considered ideal. 59 non-diabetic patients served as the control group. Their mean age was $61.2 \pm 15.0$ years, mean height $164.0 \pm 7.6 \mathrm{~cm}$ and mean body weight $103 \%$ of the ideal body weight. 11 diabetic and 11 non-diabetic patients had signs of recent transient ischaemic attacks and 11 diabetic and 11 non-diabetic patients had a manifest stroke syndrome. 22 of the diabetic patients with normal kidney function received insulin, 23 patients received oral hypoglycemic drugs ( 14 of them were treated with sulfonylureas and 9 with phenformin) 16 patients were on a low carbohydrate diet only. These groups were compared with 6 diabetic patients (all on insulin) with impaired kidney function and with 18 non-diabetic uremic patients.

All diabetic patients were kept on a low carbohydrate and sorbitol-free diet for at least two days prior to lumbar puncture. The non-diabetic patients were kept on a sorbitol-free diet.

Cerebrospinal fluid (CSF) polyols, plasma and CSF glucose were determined from all patients. Also the 
plasma polyol levels were determined from 25 of the diabetic and 27 of the non-diabetic patients.

\section{Determination of Polyols}

After at least one week of hospitalisation $2 \mathrm{ml}$ of cerebrospinal fluid was taken by lumbar puncture. 4 $\mathrm{ml}$ of heparinized whole blood was taken within the same hour and the plasma was immediately separated by centrifugation. The samples were kept deep-frozen until prepared for gas-liquid chromatography (GLC). CSF polyols were measured by GLC according to a method described recently [9].

A modified method was used to determine the plasma polyols: protein were removed from $0.5 \mathrm{ml}$ of plasma with $1.0 \mathrm{ml} 10 \%$ TCA. $1.0 \mathrm{ml}$ of the clear supernatant was taken after centrifugation and TCA was extracted with diethylether. From the neutral suspension glucose was removed with hexokinase (Boehringer, Mannheim). The removal of anions and cations was completed by using a mixed resin bed (Amberlite resin IR $120 \mathrm{CH}^{\circledR}$ and Deacidite FF-IP SRA, Permutit ${ }^{\circledR}$ ).

The remaining solution was dried in hot air and the polyols converted to acetylated forms with acetic anhydride [9]. Ribitol was used as an internal standard. A standard mixture of the following polyols: erythritol, ribitol, arabinitol, 1,5-anhydroglucitol, xylitol, mannitol, sorbitol and myoinositol was recorded at the beginning and the end of every GLC recording and the retention times were used as reference values. The detection limit for the polyols was $5 \mu \mathrm{mol} / \mathrm{l}$.

Table 1. Plasma glucose, CSF glucose and CSF sorbitol in diabetic patients and controls with normal kidney function

\begin{tabular}{llll}
\hline $\begin{array}{l}\text { Patients and } \\
\text { treatment }\end{array}$ & $\begin{array}{l}\text { Plasma glucose } \\
\mathrm{mmol} / \mathrm{l}^{\mathrm{b}}\end{array}$ & $\begin{array}{l}\mathrm{CSF} \text { glucose } \\
\mathrm{mmol} / \mathrm{l}\end{array}$ & $\begin{array}{l}\mathrm{CSF} \text { sorbitol } \\
\mu \mathrm{mol} / \mathrm{l}\end{array}$ \\
\hline $\begin{array}{l}\text { Insulin (22) } \\
\text { a }\end{array}$ & $13.0 \pm 4.0$ & $5.8 \pm 2.3$ & $\begin{array}{l}64.5 \pm 70.5 \\
p<0.001^{\mathrm{c}}\end{array}$ \\
$\begin{array}{l}\text { Oral hypoglycemic } \\
\text { drugs (23) }\end{array}$ & $6.8 \pm 2.9$ & $4.7 \pm 2.0$ & $\begin{array}{l}37.0 \pm 17.0 \\
p<0.001\end{array}$ \\
$\begin{array}{l}\text { Carbohydrate } \\
\text { restriction (16) }\end{array}$ & $4.9 \pm 1.6$ & $3.6 \pm 1.2$ & $\begin{array}{l}35.0 \pm 11.0 \\
p<0.002\end{array}$ \\
$\begin{array}{l}\text { Non-diabetic } \\
\text { patients (59) }\end{array}$ & $4.1 \pm 1.0$ & $3.5 \pm 2.0$ & $22.0 \pm 7.0$ \\
\hline
\end{tabular}

\footnotetext{
${ }^{a}$ Figures in parenthesis indicate the number of patients

b Mean and SEM

${ }^{c} \mathrm{p}$ values indicate the significance of difference between the test group and non-diabetic controls
}

\section{Determination of Plasma and CSF Glucose}

The capillary plasma and cerebrospinal fluid glucose levels were measured with a Beckman glucose analyzer using glucose oxidase (Boehringer, Mannheim). Plasma creatinine concentrations were determined in an autoanalyzer (Technicon) according to the method suggested in the manual (Method AA II-11). The significance of the results was tested with the Mann-Whitney U-test for non-parametric statistics and by calculating the correlation coefficient $r$. The significane of $r$ was tested with the following formula:

$$
{ }^{t} \mathrm{n}-2=\frac{\mathrm{r} \cdot \sqrt{\mathrm{n}-2}}{\sqrt{1-\mathrm{r}^{2}}}
$$

were ${ }^{t} n-2$ is distributed according to the student distribution with $\mathrm{n}-2$ degrees of freedom when $\varrho=0$

\section{Results}

\section{CSF Polyol Levels in Diabetic Patients with Normal Kidney Function}

1. CSF Sorbitol. The mean level of CSF sorbitol was $40.5 \pm 30.0 \mu \mathrm{mol} / \mathrm{l}$ in the diabetic group compared with $22.0 \pm 7.0 \mu \mathrm{mol} / 1$ in the non-diabetic control group. The difference is significant $(p<0.001)$ (Table 1).

The insulin-receiving diabetic patients had higher sorbitol levels (mean $64.5 \pm 70.5 \mu \mathrm{mol} / \mathrm{l}$ ) and plasma glucose levels (mean $13.0 \pm 4.0 \mathrm{mmol} / \mathrm{l}$ ) than did patients receiving oral hypolgycemic drugs (mean $37.0 \pm 17.0 \mu \mathrm{mol} / \mathrm{l}$ for sorbitol and $6.8 \pm 2.9 \mathrm{mmol} / \mathrm{l}$ for plasma glucose). Patients on carbohydrate restriction only had the lowest mean levels of CSF sorbitol $(35.0 \pm 11.0 \mu \mathrm{mol} / \mathrm{l})$ and plasma glucose $(4.9 \pm 1.6$ $\mathrm{mmol} / \mathrm{l}$ ) (Table 1).

CSF sorbitol correlated positively with the plasma glucose level in patients who had received insulin for less than 12 months $(r=0.65)$. There was, however, no correlation between plasma glucose and CSF sorbitol levels in patients who had been insulin-dependent for more than 10 years. The CSF sorbitol level was low in all cases (Fig. 1).

The patients were grouped according to duration and type of diabetes and the state of kidney function (Fig. 2). High CSF sorbitol levels were seen in insulindependent diabetic patients with long duration of the disease and impaired kidney function (Fig. 2, Group A). Another group with high sorbitol levels in CSF consisted of old patients who had suffered from maturity onset type of diabetes for many years and were not dependent on insulin, but had recently been 
put on insulin treatment because of severe hyperglycemia during an acute illness (pyelonephritis, sepsis or cerebral ischemic attack) (Fig. 2, Group B). None of these patients were given intravenous infusions when lumbar puncture was performed. A third group with high CSF sorbitol levels consisted of 5 patients whose diabetes had been diagnosed recently (less than 6 months duration) and who had been insulin-dependent from the beginning (Fig. 2, Group C). Fig. 2 also presents data obtained from other insulin-dependent diabetics with normal kidney function (Fig. 2, Group D) and 18 non-diabetic uremic patients (Fig. 2, Group E).

The dashed area in Fig. 2 indicates the normal range for CSF sorbitol in non-diabetic control patients. The sorbitol level in CSF was significantly elevated in all diabetic groups compared with non-diabetic and uremic patients.

In order to find out whether artificially sustained hyperglycemia may result in a change in the sorbitol level in CSF, samples were taken from four nondiabetic patients (fasting blood sugar normal, oral glucose tolerance test normal) who, as part of their treatment, received $1000-1500 \mathrm{ml} 5 \%$ glucose per day intravenously for 2-3 days. A sample was taken for CSF sorbitol and plasma glucose determination at the end of the period. An almost two-fold increase of CSF sorbitol was noted in these non-diabetic patients, suggesting that hyperglycemia per se, sustained for this short period, resulted in an increased sorbitol production (Table 2 ).

2. CSF 1,5-Anhydroglucitol. 1,5-anhydroglucitol was absent from CSF in all diabetic patients receiving insulin (Table 3, Fig. 2, Group A and B). Those diabe-

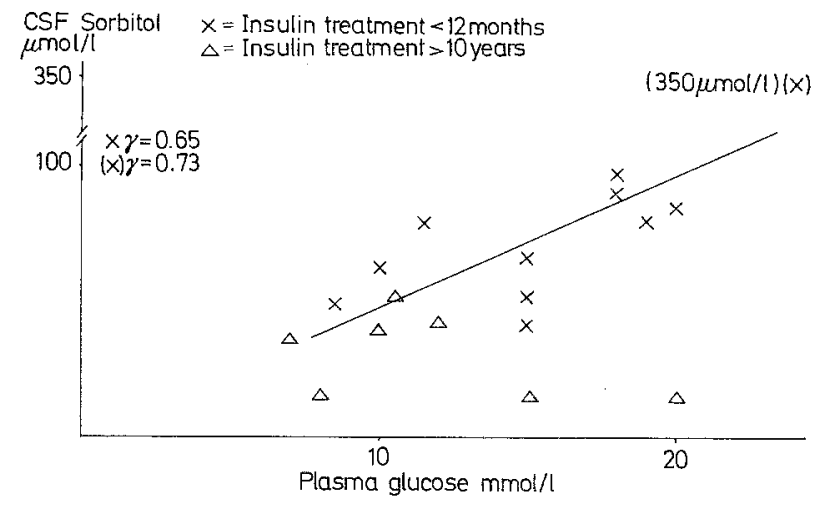

Fig. 1. The correlation between CSF sorbitol and plasma glucose levels in diabetic patients receiving insulin and having been treated with insulin for either less than 12 months or more than 10 years. One very high sorbitol concentration $(x)$ was included. The correlation coefficients given refer to the data with or without inclusion of this one high value tic patients receiving oral hypoglycemic drugs or who were under carbohydrate restriction had normal anhydroglucitol levels in the CSF samples. The anhydroglucitol level in CSF showed no correlation with plasma glucose level or duration of diabetes.

3. CSF Myoinositol. The myoinositol levels in CSF were similar in diabetic and non-diabetic patients (Table 3). Insulin-dependent diabetic patients had the lowest mean level of CSF myoinositol, but the difference between this level and the mean level of the non-diabetic patients was not significant. CSF myoinositol did not correlate with plasma glucose level or duration of the disease.

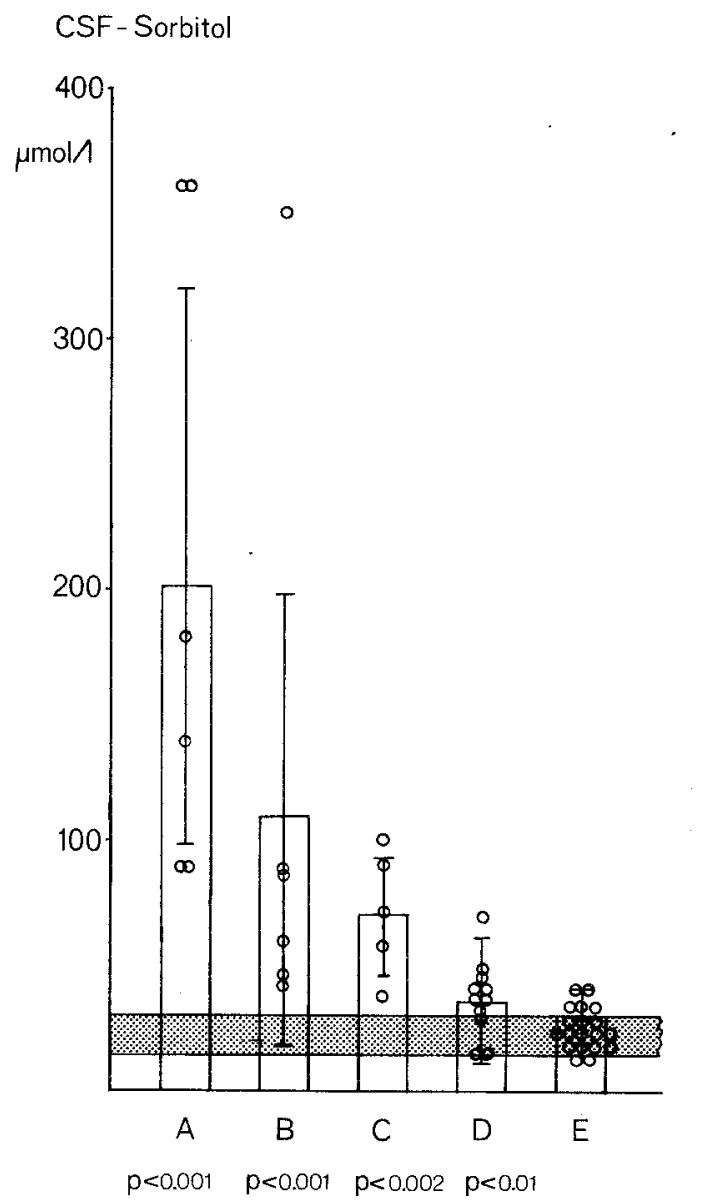

Fig. 2. The CSF sorbitol level in diabetic patients receiving insulin and in uremic non-diabetic patients. $\mathrm{A}=$ diabetic patients with impaired kidney function. $\mathrm{B}=$ diabetic patients not suffering from insulin-dependent diabetes, but shifted to insulin treatment because of severe hyperglycemia during an acute illness. $\mathrm{C}=$ diabetic patients suffering from insulin-dependent diabetes and treated with insulin for less than 12 months. $\mathrm{D}=$ other diabetic patients receiving insulin. $\mathrm{E}=$ non-diabetic uremic patients. The dashed area indicates mean \pm SEM for non-diabetic controls: the $p$ values indicate significance of difference between test groups and the control group 


\section{CSF Polyol Levels in Diabetic and Non-Diabetic Patients with Impaired Kidney Function}

The patients with impaired kidney function, both diabetic and non-diabetic, had significantly elevated mean levels of myoinositol in CSF $(p<0.001)$ (Table 4). The CSF sorbitol level was significantly elevated in the diabetic patients. 1,5-anhydroglucitol was absent from the CSF of the diabetic group and very low in the non-diabetic uremic patients.

\section{Comparison between Polyol Levels in Plasma and CSF}

Both plasma and CSF samples were obtained from 22 diabetic and 23 non-diabetic patients with normal kidney function, and from 2 diabetic and 5 nondiabetic patients with elevated plasma creatinine, respectively.

1. Patients with Normal Kidney Function. Sorbitol was undetectable (below detection limits for GLC) in the plasma of these patients. 1,5-anhydroglucitol was present in the plasma of all non-diabetic patients and in the plasma of diabetic patients not receiving insulin. In contrast, it was absent from the plasma of diabetic patients receiving insulin (Table 5). The plasma myoinositol was significantly lower in the plasma $(p<$ 0.001 ) than in the CSF of patients with normal kidney function.

2. Patients with Impaired Kidney Function. The plasma myoinositol level was elevated in all patients with impaired kidney function (Table 6). The CSF myoinositol level was also elevated but less so than the plasma level. In 3 out of 7 patients the myoinositol level was higher in the plasma than in the CSF. Sorbitol was undetectable in the plasma, and 1,5-anhydroglucitol low or undetectable.

The plasma myoinositol level was correlated with the plasma creatinine level in the patients with impaired kidney function (Fig. 3).

\section{Discussion}

\section{Sorbitol}

Our present study supports previous reports $[6,9$, $10,12]$ that diabetes profoundly changes the polyol metabolism in man.

Hyperglycemia is followed by an increase in CSF sorbitol in diabetic and obviously also in non-diabetic patients. CSF sorbitol was correlated significantly with plasma glucose in diabetic patients chronically receiving insulin and having recently been put on insu-
Table 2. CSF sorbitol and 1,5-anhydroglucitol levels in four nondiabetic patients who received $1000-1500 \mathrm{ml} 5 \%$ glucose intravenously daily for 2-3 days before lumbar puncture

\begin{tabular}{lcll}
\hline Patients $^{\mathrm{a}}$ & Plasma glucose & CSF sorbitol & $\begin{array}{l}\text { CSF 1,5-anhydro- } \\
\text { glucitol } \\
\mu \mathrm{mol} / \mathrm{l}\end{array}$ \\
& $\mathrm{mmol} / 1$ & $\mu \mathrm{mol} / \mathrm{l}$ & 68.5 \\
1. & 8.3 & 47.0 & 69.0 \\
2. & 10.7 & 39.0 & 105.0 \\
3. & 7.0 & 39.0 & 75.0 \\
4. & 13.7 & 30.0 & $87.0 \pm 30.0$ \\
\hline
\end{tabular}

a Oral GTT and fasting blood glucose levels normal, plasma creatinine level normal.

Table 3. Cerebrospinal fluid levels of 1,5-anhydroglucitol and myoinositol in diabetic and non-diabetic patients with normal kidney function (for footnotes see Table 1)

\begin{tabular}{lll}
\hline $\begin{array}{l}\text { Patients } \\
\text { and treatment }\end{array}$ & $\begin{array}{l}\text { CSF 1,5-anhydroglucitol } \\
\mu \mathrm{mol} / \mathrm{b}^{\mathrm{b}}\end{array}$ & $\begin{array}{l}\mathrm{CSF} \text { myoinositol } \\
\mu \mathrm{mol} / \mathrm{l}^{\mathrm{b}}\end{array}$ \\
\hline $\begin{array}{l}\text { Insulin }(22)^{\mathrm{a}} \\
\begin{array}{l}\text { Oral hypoglycemic } \\
\text { drugs (23) }\end{array}\end{array}$ & below 5 & $113.0 \pm 52.0$ \\
$\begin{array}{l}\text { Carbohydrate } \\
\text { restriction (16) }\end{array}$ & $90.0 \pm 70.0$ & $152.0 \pm 51.0$ \\
$\begin{array}{l}\text { Non-diabetic } \\
\text { patients (59) }\end{array}$ & $87.0 \pm 30.0$ & $149.0 \pm 26.0$ \\
\hline
\end{tabular}

Table 4. CSF sorbitol, 1,5-anhydroglucitol and myoinositol levels in diabetic patients with impaired kidney function and uremic nondiabetic patients

\begin{tabular}{llll}
\hline Patients & CSF sorbitol & CSF & CSF \\
& $\mu \mathrm{mol} / 1$ & $\begin{array}{l}1,5 \text {-anhydro- } \\
\text { glucitol }\end{array}$ & $\mu \mathrm{mol} / \mathrm{mositol}$ \\
& & $\mu \mathrm{mol} / 1$ & \\
& &
\end{tabular}

Diabetic patients $^{\mathrm{a}}$

(6) plasma

creatinine

$250 \pm 40 \mu \mathrm{mol} / \mathrm{l}$
$201.0 \pm 128.0$ below $5.0 \quad 216.0 \pm 78.0$
$p<0.001 \quad p<0.001 \quad p<0.001$
$30.0 \pm 7.0$
$20.0 \pm 17.0 \quad 196.0 \pm 56.0$
$p<0.001 \quad p<0.002$

Uremic patients not

on dialysis (8)

plasma creatinine

$905 \pm 200 \mu \mathrm{mol} / 1$

Uremic patients on

dialysis (10)

plasma creatinine

$820 \pm 300 \mu \mathrm{mol} / 1$

Normal values

(59)

$$
\begin{array}{lll}
27.5 \pm 6.0 & \text { below 10.0 } & 273.0 \pm 58.0 \\
& p<0.001 & p<0.001 \\
22.0 \pm 7.0 & 87.0 \pm 30.0 & 138.0 \pm 50.0
\end{array}
$$

${ }^{a} \mathrm{p}$ values indicate the significance of difference between the test group and non-diabetic non-uremic controls. The number of patients in each group is given in parentheses. 
Table 5. Plasma levels of sorbitol, 1,5-anhydroglucitol and myoinositol in diabetic and non-diabetic patients with normal kidney function

\begin{tabular}{llll}
\hline $\begin{array}{l}\text { Patients and } \\
\text { treatment }\end{array}$ & $\begin{array}{l}\text { Plasma } \\
\text { sorbitol }\end{array}$ & $\begin{array}{l}\text { Plasma } \\
1.5 \text {-anhydro- } \\
\text { glucitol } \\
\mu \mathrm{mol} / \mathrm{l}\end{array}$ & $\begin{array}{l}\text { Plasma } \\
\text { myoinositol }\end{array}$ \\
\hline $\begin{array}{l}\mu \mathrm{mol} / \mathrm{l} \\
\text { Insulin (12) }\end{array}$ & below 5.0 & $\begin{array}{l}\text { below } 5.0 \\
p<0.001\end{array}$ & $\begin{array}{l}31.0 \pm 10.0 \\
p<0.001^{\mathrm{a}}\end{array}$ \\
$\begin{array}{l}\text { Oral hypolgycemic } \\
\text { drugs or carbohy- } \\
\text { drate restriction }\end{array}$ & & & \\
$\begin{array}{l}\text { (10) } \\
\text { Non-diabetic }\end{array}$ & below 5.0 & $96.0 \pm 50.0$ & $\begin{array}{l}25.0 \pm 5.0 \\
p<0.001\end{array}$ \\
$\begin{array}{l}\text { patients (23) } \\
\text { below 5.0 }\end{array}$ & $99.5 \pm 30.5$ & $\begin{array}{l}28.0 \pm 12.0 \\
p<0.001\end{array}$ \\
\hline $\begin{array}{l}\text { Normal CSF } \\
\text { values }\end{array}$ & $22.0 \pm 7.0$ & $87.0 \pm 30.0$ & $138.0 \pm 50.0$ \\
\hline
\end{tabular}

${ }^{a} \mathrm{p}$ value indicates significance of difference between plasma level and CSF level of myoinositol.

Table 6. CSF and plasma levels of myoinositol in two diabetic and five non-diabetic patients with impaired kidney function

\begin{tabular}{llcll}
\hline & & $\begin{array}{l}\text { Plasma } \\
\text { myoinositol } \\
\mu \mathrm{mol} / 1\end{array}$ & $\begin{array}{l}\text { CSF } \\
\text { myoinositol } \\
\mu \mathrm{mol} / \mathrm{l}\end{array}$ & $\begin{array}{l}\text { Plasma } \\
\text { creatinine } \\
\mu \mathrm{mol} / \mathrm{l}\end{array}$ \\
\hline Diabetic & I.P. & 66.0 & 144.0 & 200.0 \\
Diabetic & E.S. & 110.0 & 168.0 & 280.0 \\
Non-diabetic & G.L. & 135.0 & 187.0 & 351.0 \\
Non-diabetic & S.I. & $150.0^{\mathrm{a}}$ & 140.0 & 341.0 \\
Non-diabetic & H.H. & 268.0 & 297.0 & 830.0 \\
Non-diabetic & P.P. & $435.0^{\mathrm{a}}$ & 253.0 & 600.0 \\
Non-diabetic & E.J. & $1263.0^{\mathrm{a}}$ & 1030.0 & 1495.0 \\
Normal values & $28.0 \pm 12.0$ & $138.0 \pm 50.0$ & \\
\hline
\end{tabular}

a Plasma myoinositol level > CSF myoinositol level.

lin. We found no correlation, however, between plasma glucose levels and CSF sorbitol levels in insulindependent patients who had received insulin for more than 10 years; in the latter group of patients CSF sorbitol did not rise above the normal range. These findings are in agreement with experimental studies concerning the activity of aldose reductase [1] which demonstrate that aldose reductase activity is high at the beginning of experimental diabetes.

Diabetic patients with impaired kidney function had significantly elevated CSF sorbitol levels. The mechanism of this elevation is unclear. Schofield et al. [4] have recently demonstrated the role of the kidneys in sorbitol metabolism by showing that monkey kid-

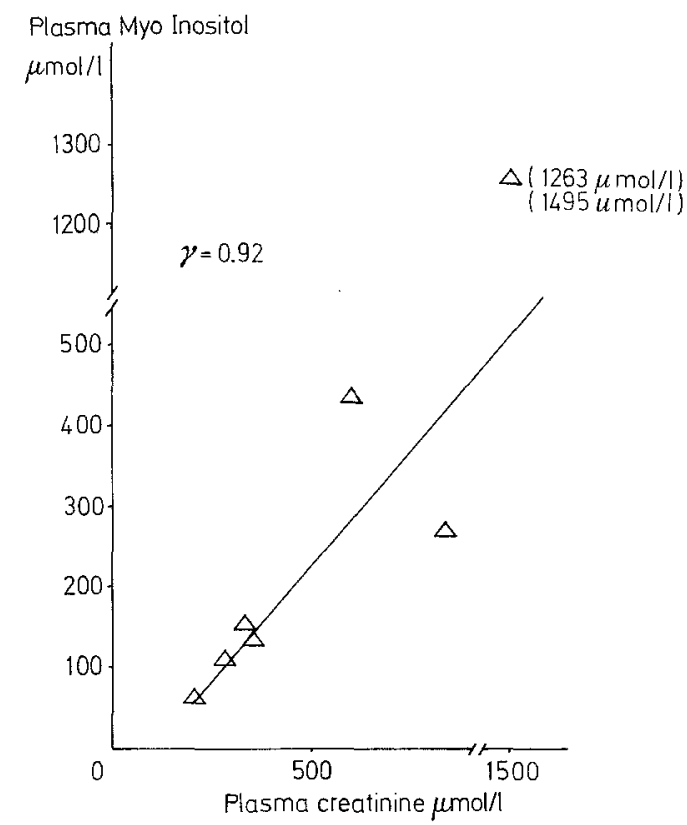

Fig. 3. The correlation between plasma creatinine level and plasma myoinositol level in 7 patients with impaired kidney function

ney epithelial cells accumulate sorbitol by means of the sorbitol pathway. In uremic patients many substrates are retained in the body because of impaired urine excretion or impaired degradation in the kidneys, but since the plasma levels were not elevated and since uremia per se did not cause sorbitol elevation in CSF, this explanation is improbable. Thus the sorbitol elevation in diabetic patients with nephropathy must be caused by the diabetic state.

Osmolar Effects of Sorbitol. Although we noted maximum CSF sorbitol concentrations of $360 \mu \mathrm{mol} / \mathrm{l}$, i. e. more than 10 times the normal level, the concentrations were still low in relation to possible osmolar effects. However, the elevation of CSF sorbitol must be a product of cellular metabolism and since penetration of sorbitol through cell membranes is slow, the elevation of CSF sorbitol may be a reflection of very high cellular levels.

\section{1,5-Anhydroglucitol}

This anhydride form of sorbitol has recently been demonstrated in human [8]. The present study verifies the previous findings that this polyol is absent from the plasma and CSF in insulin-receiving diabetic patients and low in advanced stages of uremia. The metabolism and role of this polyol is unknown. We found no correlation with the severity of the complications of either the diabetic or uremic state. 


\section{Myoinositol}

Myoinositol was elevated both in the plasma and CSF of patients with impaired kidney function. The plasma level was correlated with plasma-creatinine level, Urine excretion of myoinositol is increased in uremia and diabetes [12]. In normal man only $0.8 \%$ of orally administered myoinositol is excreted in the urine; the remaining $99.2 \%$ is degraded [10]. Our studies support the theory that the kidneys [12] degrade myoinositol normally and that this degradation is impaired in uremic patients. Thus the elevation of plasma myoinositol in uremia can partly be explained by an impaired degradation in the kidneys.

We have shown that there are similarities as well as differences in the polyol metabolism in diabetic and uremic patients. In both groups the 1,5-anhydroglucitol level decreases in the plasma and CSF, but in diabetic patients this decrease is seen only in those patients receiving insulin. The myoinositol level is elevated in relation to the impairment of kidney function in uremia as well as in diabetes. The sorbitol level is significantly elevated in the CSF of diabetic patients, but no elevation was noted in the uremic patients. The elevation of sorbitol correlated significantly with the plasma glucose level in the early stages of insulin-dependent diabetes and in non-diabetic subjects receiving glucose infusions, indicating that the sorbitol elevation was caused by an increase in the glucose level. However, no such relationship was observed in cases of diabetes of long duration. The reasons for this is unknown, but it may be related to the changes in aldose reductase levels which have been observed in studies of diabetes in experimental animals [1]. The myoinositol excretion was increased in diabetes; the plasma and CSF levels of myoinositol were however, normal. Whether the increased excretion was due to increased synthesis or decreased degradation in the kidneys is not known.

Acknowledgement. This investigation was supported by $\mathrm{Re}$ search Grant from Sigrid Jusélius Foundation, Helsinki.

\section{References}

1. Gabbay, K.F.: The sorbitol pathway and the complications of diabetes. New Engl. J. Med. 288, 831-836 (1973)

2. Ward, J.D., Baker, R.W.R., Davies, B.H.: Effect of blood sugar control on the accumulation of sorbitol and fructose in nervous tissue. Diabetes 21, 1973-1978 (1972)

3. Gabbay, K.H.: Factors affecting the sorbitol pathway in diabetic nerve. Diabetes 18 (Suppl. 1), 336-337 (1969)

4. Schofield, P.J., Hutton, J.C., Williams, J.F.: Polyol synthesis by monkey kidney epithelial cells in culture. IRCS (Research on: biochemistry; biophysics, membrane and cell biology; kidneys and urinary system; metabolism and nutrition) 2, 1465 (1974)

5. de Jesus, P.V., Clements, R.S., Winegrad, A.I.: Hypermyoinositolemic polyneuropathy in rats. J. neurol. Sci. 21, 237-249 (1974)

6. Clements, R.S.: Myoinositol metabolism in diabetes mellitus. Diabetes 23 (Suppl. 1, Abstract), 348 (1974)

7. Clements, R.S., de Jesus, P.V., Winegrad, A.I.: Raised plasma myoinositol levels in uremia and experimental neuropathy. Lancet 1973 I, 1137-1141

8. Pitkänen, E.: Occurence of 1,5-anhydroglucitol in human cerebrospinal fluid. Clin. chim. Acta 48, 159-166 (1973)

9. Pitkänen, E., Servo, C.: Cerebrospinal fluid polyols in patients with diabetes mellitus. Clin. chim. Acta 44, 437-442 (1973)

10. Daughaday, W.H., Larner, J.: Renal excretion of inositol in normal and diabetic human beings. J. clin. Invest. 33, 326-332 (1954)

11. Malaisse, W.J., Sener, A., Mahy, M.: The stimulus-secretion coupling of glucose induced insulin release. Sorbitol metabolism in isolated islets. Europ. J. Biochem. 47, 365-370 (1974)

12. Pitkänen, E.: The serum polyol pattern and the urinary polyol excretion in diabetic and uremic patients. Clin. chim. Acta 38, 221-230 (1972)

13. Servo, C.: The sorbitol level in CSF in diabetic patients. Acta Endocrinol. (Kbh.) 77, (Suppl. 190, Abstract), 80 (1974)

C. Servo, M.D.

Fourth Dept. of Medicine

Univ. of Helsinki

SF-00170 Helsinki 17

Finland 